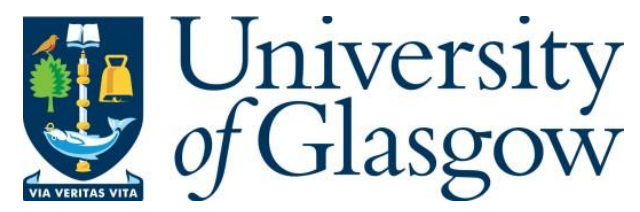

Clark, M. E. et al. (2018) Lung cancer screening: does pulmonary nodule detection affect a range of smoking behaviours? Journal of Public

Health, (doi:10.1093/pubmed/fdy158)

There may be differences between this version and the published version. You are advised to consult the publisher's version if you wish to cite from it.

http://eprints.gla.ac.uk/170991/

Deposited on: 1 November 2018

Enlighten - Research publications by members of the University of Glasgow http://eprints.gla.ac.uk 


\title{
Lung cancer screening: Does pulmonary nodule detection affect a range of smoking behaviours?
}

\author{
Authors \\ Dr Marcia E Clark, Academic Clinical Fellow, Division of Primary Care, Floor 13, Tower Building, \\ University Park, University of Nottingham, Nottingham, NG7 2RD. \\ Ben Young, PhD student, Division of Primary Care, Floor 13, Tower Building, University Park, University \\ of Nottingham, Nottingham, NG7 2RD. \\ Laura E Bedford, Research Fellow, School of Pharmacy, Queen's University Belfast, 97 Lisburn Road, \\ Belfast, BT9 7BL. \\ Prof John FR Robertson, Professor of Surgery, Faculty of Medicine and Health Sciences, University of \\ Nottingham, Queen's Medical Centre, Nottingham, NG7 2UH \\ Prof Roshan das Nair, Professor of Clinical Psychology \& Neuropsychology, C22, Institute of Mental \\ Health, Jubilee Campus, University of Nottingham, Nottingham, NG8 1BB \\ Prof Kavita Vedhara, Professor of Health Psychology, Division of Primary Care, Floor 13, Tower \\ Building, University Park, University of Nottingham, Nottingham, NG7 2RD \\ Prof Francis Sullivan, Professor of Primary Care Medicine, University of St Andrews, School of \\ Medicine, North Haugh, St Andrews, KY16 9TF \\ Prof Frances S Mair, Norie Miller Professor of General Practice, Head of General Practice and Primary \\ Care, Institute of Health and Wellbeing, MVLS, University of Glasgow, 1 Horselethill Road, Glasgow, \\ G12 9LX \\ Dr Stuart Schembri, Consultant in Respiratory Medicine, Scottish Centre for Respiratory Research, \\ University of Dundee, Ninewells Hospital and Medical School, Dundee, DD1 9SY \\ Dr Roberta C Littleford, Assistant Director, Tayside Clinical Trials Unit (TCTU), Tayside Medical \\ Science Centre (TASC), University of Dundee, School of Medicine, Ninewells Hospital and \\ Medical School, Residency Block, Level 3, George Pirie Way, Dundee DD1 9SY \\ *Prof Denise Kendrick, Professor of Primary Care Research, Division of Primary Care, Floor 13, Tower \\ Building, University Park, University of Nottingham, Nottingham, NG7 2RD
}

*Corresponding author

Email address: denise.kendrick@nottingham.ac.uk

Abstract word count: 200

Article word count: 2950 (excluding abstract, references, tables and figures) 


\begin{abstract}
Background

Lung cancer screening can reduce lung cancer mortality by $20 \%$. Screen-detected abnormalities may provide teachable moments for smoking cessation. This study assesses impact of pulmonary nodule detection on smoking behaviours within the first UK trial of a novel auto-antibody test, followed by chest x-ray and serial CT scanning for early detection of lung cancer (Early Cancer Detection Test-Lung Cancer Scotland Study).
\end{abstract}

\title{
Methods
}

Test-positive participants completed questionnaires on smoking behaviours at baseline, 1, 3 and 6 months. Logistic regression compared outcomes between nodule $(n=95)$ and normal CT groups $(n=174)$ at 3 and 6 months follow-up.

\section{Results}

No significant differences were found between the nodule and normal CT groups for any smoking behaviours and odds ratios comparing the nodule and normal CT groups did not vary significantly between 3 and 6 months. There was some evidence the nodule group were more likely to report significant others wanted them to stop smoking than the normal CT group (OR across 3 and 6 month time points: $3.04,95 \% \mathrm{Cl} 0.95,9.73 ; \mathrm{p}=0.06)$.

\section{Conclusion}

Pulmonary nodule detection during lung cancer screening has little impact on smoking behaviours. Further work should explore whether lung cancer screening can impact on perceived social pressure and promote smoking cessation.

\section{Keywords}

Pulmonary nodules, lung cancer screening, smoking behaviour 


\section{Introduction}

Lung cancer is the most common cause of cancer-related death, with approximately 1.59 million deaths worldwide in 2012. ${ }^{1}$ Despite 1-year survival in England improving from 17\% in 1990 to 29\% and $33 \%$ for men and women respectively in $2010,{ }^{2}$ mortality remains high, with a 5 -year survival rate in England and Wales of only 9.5\%. ${ }^{1}$ In Scotland, both lung cancer incidence and mortality are significantly higher than those for England, Wales and Northern Ireland. ${ }^{1}$

Lung cancer mortality could be reduced with screening. The National Lung Cancer Screening Trial (NLST) showed serial computed tomography (CT) scanning reduced lung cancer mortality by $20 \%{ }^{3}$ However, before introduction of screening programmes, it is necessary to ensure that the overall benefits outweigh the harms. ${ }^{4}$ Pulmonary nodules, an incidental finding, are an example of a potential harm ${ }^{5}$ and were found in $25 \%$ of screened individuals in the NLST. ${ }^{3}$ Pulmonary nodules are widely defined as lesions in the lung less than $3 \mathrm{~cm}$ in diameter that are entirely surrounded by normal lung tissue. ${ }^{6,7}$ Depending on size and patient history they are regularly monitored for changes for 1-5 years. $^{8}$ As a result, individuals found to have pulmonary nodules may perceive that regular surveillance means that smoking cessation is not necessary, reducing motivations to quit. ${ }^{9}$ Concern has also been expressed that those with normal CT scans may interpret this as a "licence to smoke". ${ }^{10}$ As the majority (85-90\%) of lung cancer is attributable to smoking and lung cancer risk reduces substantially (by $80-90 \%$ ) after smoking is stopped for more than 15 years ${ }^{11}$, it is important to assess the impact of CT findings from lung cancer screening on smoking behaviour. Several lung cancer screening studies from outside the UK have shown that individuals with an abnormal CT scan (including pulmonary nodules) are more likely to remain abstinent from smoking or stop smoking than those with a normal CT scan. ${ }^{10,12-17}$ More recently, the UK Lung Cancer Screening Trial (UKLS) reported no significant effect of needing additional investigations following an abnormal CT result on smoking cessation compared to those with a negative CT result in the short term (approximately 2 weeks following $\mathrm{CT}$ result). However, those needing additional investigations were significantly more likely to have stopped smoking up to 2 years later than those with a negative CT result. ${ }^{18}$

The Early Cancer Detection Test - Lung Cancer Scotland Study (ECLS Study) ${ }^{19}$ is evaluating use of a novel auto-antibody test ${ }^{20}$ as a method of case finding in lung cancer screening. This differs from previous lung cancer screening studies, as only those with a positive auto-antibody test receive CT scanning. Our study assesses the short and medium-term impact on self-reported smoking behaviour, intentions, confidence in stopping smoking, motivation, perceived health benefits and social pressure 
to stop smoking amongst auto-antibody test positive participants in the ECLS study, comparing those who were and those who were not found to have pulmonary nodules on their first CT scan.

\section{Methods}

The ECLS study is a randomised controlled trial assessing the effectiveness of a blood test, measuring autoantibodies against seven antigens (Early $\mathrm{CDT}^{\circledR}{ }^{-}$-Lung test) as a technique for lung cancer screening. ${ }^{19,} 20$ Individuals from Greater Glasgow and Clyde or Tayside NHS board areas were invited to participate in the study if they were aged $50-75$ years with a minimum of a 20 pack-year smoking history (current and ex-smokers) or those with fewer pack-years and a first degree relative with lung cancer. Participants completed a baseline questionnaire prior to randomisation to an Early CDT ${ }^{\circledR}{ }^{-L u n g}$ test group or a non-screened control group. Those with positive Early CDT ${ }^{\oplus}$-Lung tests were given verbal and written information explaining the subsequent investigations; a chest $\mathrm{x}$-ray and CT scan, followed by 6 -monthly CT scans for 2 years. The potential for finding a pulmonary nodule on their CT scan was also explained. The majority of CT scan results were provided in writing, with a small number given verbally.

ECLS study participants who consented to be contacted were invited to participate in a sub-study, assessing psychological and behavioural responses to lung cancer screening. Additional questionnaires were completed at $1,3,6$ and 12 months by those in the control and Early CDT ${ }^{\circledR}$ negative groups and at 1, 3, 6, 12, 18 and 24 months in the Early CDT ${ }^{\circledR}$-positive group. Responders to questionnaires were sent a $f 5$ gift voucher. Non-responders were given postal and telephone reminders. This paper presents analyses of outcomes in relation to smoking behaviours (short and medium-term impact on self-reported smoking behaviour, intentions, confidence in stopping smoking, motivation, perceived health benefits and social pressure to stop smoking) from participants in the Early $\mathrm{CDT}^{\circledR}$-positive group who completed baseline and at least one follow-up questionnaire at 3 or 6 months, and had a CT scan within the first three months of the study. 1 month follow-up data was not used in these analyses as most participants had not received their CT scan results at this time point. Those with pulmonary nodule(s) $\leq 8 \mathrm{~mm}$ in diameter on their first CT scan were categorised as being in the nodule group and those with a normal CT (this includes those with previously known stable pathology) were categorised as being in the normal CT group. Those diagnosed with lung cancer, those withdrawing from the study, those with CT findings other than normal or nodule(s) $\leq 8 \mathrm{~mm}$ in diameter and those not responding to $\geq 2$ consecutive follow-up questionnaires were ineligible for the current study. 


\section{Data collection}

Participant baseline demographics including age, gender, smoking history, ethnic group, marital status, postcode, age at leaving full time education, employment status, family history of lung cancer (first-degree relative) and antidepressant medication use was collected at trial recruitment between December 2013 and April 2015. Baseline data was collected prior to receiving the Early CDT ${ }^{\circledR}$-Lung test result. A number of questions were used to determine smoking behaviours for those participants who had smoked cigarettes or tobacco during the previous week. Supplementary Table I summarises the data collected.

\section{Analysis}

Data analysis was undertaken using Stata Statistical Software version 13.1. ${ }^{21}$ Continuous baseline characteristics were non-normally distributed and are described using medians and interquartile ranges (IQR). Frequencies and percentages were used to describe categorical data. Baseline data for the normal CT and nodule groups was compared using chi-squared tests and Mann-Whitney $\mathrm{U}$ tests for categorical and continuous variables respectively. Fisher's exact test was used where expected numbers were small.

Logistic regression models, with standard errors adjusted to account for multiple responses per participant, were used to compare smoking behaviours between the normal CT and nodule groups. Group by time interaction terms were added to models to assess whether any differences between the nodule and normal CT groups varied between 3 and 6 months, with a $p$-value of $<0.01$ taken as significant. Where there were no significant differences over time, a single odds ratio was presented across all follow-up time points. The number of cigarettes smoked per day was the only continuous outcome. Model checking indicated residual values were not normally distributed with constant variance. Assumptions were still not met using a logarithmic transformation, hence the number of cigarettes smoked per day was dichotomised into <median or $\geq$ median and analysed using logistic regression as described above. In the main analysis, models were adjusted for baseline values of the outcome variable. In addition, models were also adjusted for study centre, age group (50-54, 55-59, 60-64, 65-69, 70-74 years), and sex as these were the minimisation variables for randomisation to Early CDT ${ }^{\oplus}$-Lung test or no-test group in the ECLS trial.

\section{Results}


Supplementary figure 1 outlines the flow of participants through the study. In total, 338 test-positive ECLS trial participants took part in the smoking behaviour study. Of these 269 (174 in the normal CT group and 95 in the nodule group) were eligible to be included in the analyses presented in this paper. Completion rates for follow-up questionnaires were $95 \%$ at 3 months and $94 \%$ at 6 months. The baseline demographics of the participants by nodule status are shown in Table I. There were no statistically significant differences between the two groups.

Table II shows baseline smoking behaviours. No significant differences were seen for any of the behaviours between the two groups. Smoking behaviours at 3 and 6 months are shown in Table III. Of note, the proportion smoking in the last week or in the period since the preceding questionnaire were lower at both follow-up time points than at baseline with similar reductions in the nodule and normal CT group (e.g. 58\% and 56\% smoking in the last week in the nodule and normal CT groups respectively at baseline compared to $47 \%$ and $46 \%$ at 3 months and $47 \%$ and $44 \%$ at 6 months respectively). Other smoking behaviours also appeared stable between 3 and 6 months in both the nodule and normal CT groups. There were few differences between the nodule and normal CT groups at 3 or 6 months for most smoking behaviours. At both 3 and 6 months, a higher proportion of nodule group participants smoked within thirty minutes of waking and were certain they could give up smoking for good and a lower proportion were trying to stop smoking than those in the normal CT group. However the differences between the nodule and normal CT group were of a similar magnitude to those at baseline (table II).

Table IV shows odds ratios across both follow-up time points, adjusted for baseline values, comparing the nodule to the normal CT group. There were no significant differences in any smoking behaviours between the nodule and normal CT groups across both follow-up time points and odds ratios comparing the nodule and normal CT groups did not vary significantly between 3 and 6 months.. There was some evidence that the nodule group were more likely to report significant others wanted them to stop smoking than the normal CT group (OR across 3 and 6 month time points: $3.04,95 \% \mathrm{Cl} 0.95$, 9.73; $p=0.06$ ). Adjusting models for study centre, age group and sex made little difference to the findings (supplementary table II).

\section{Discussion}

Main study findings 
This study found being diagnosed with pulmonary nodules following lung cancer screening with a positive Early $\mathrm{CDT}^{\circledR}$-test and a CT scan appeared to have little impact on smoking behaviour, intentions, confidence in stopping smoking, motivation or perceived health benefits. Being diagnosed with pulmonary nodules may impact on social pressure to stop smoking as there was some evidence that those with pulmonary nodules were more likely to report that significant others wanted them to stop compared to the normal CT group.

\section{What is already known on this topic?}

A small number of studies have explored smoking behaviour of individuals diagnosed with pulmonary nodules during lung cancer screening. A systematic review in $2014^{22}$ reported findings from five studies, ${ }^{10,12,13,23,24}$ with three studies finding significantly higher abstinence rates amongst those with CT results that were concerning, but not diagnostic for lung cancer, than in those whose scan results were not concerning for lung cancer. ${ }^{12,13,23}$ They also found that a higher number of abnormal CT results may be associated with higher abstinence rates. ${ }^{22}$ However, two studies failed to find a significant difference between those with and without abnormal CT results, ${ }^{10,24}$ and our findings are consistent with these. A more recent UK study also found those needing additional investigations were significantly more likely to stop smoking up to 2 years after screening than the control group or the screen negative group. ${ }^{18}$ Studies showing higher abstinence rates in those with abnormal CT results ${ }^{12,}$ $13,18,23$ had similar study populations to ours, but had longer follow-up periods or a greater number of screening rounds and most had lower follow-up rates. ${ }^{12,18,23}$ These studies also used different measures of smoking behaviour than in our study. These differences may account for variation in findings between these studies and our study. Our finding that smoking behaviours appeared stable over time in the normal CT group suggests a normal result is not being interpreted by participants as a "licence to smoke". This is consistent with findings from several previous studies. ${ }^{10,14,18}$

Why might a positive Early $\mathrm{CDT}^{\circledR}{ }^{\circledR}$-test coupled with pulmonary nodules on CT scan have little impact on smoking behaviour? Both groups showed reductions in smoking prevalence at 3 and 6 months compared to baseline so the positive EarlyCDT-Lung test may have had a greater impact on smoking than the finding of pulmonary nodules on CT scans. One potential explanation is that those in the nodule group may have been provided with a degree of reassurance because they may have perceived their nodules as a reason for having a positive Early $\mathrm{CDT}^{\circledR}{ }^{\circledR}$-Lung test. This is supported by a qualitative study from America, which found individuals diagnosed with nodules felt that this meant that screening was working, that lung nodules represented lung cancer found so early that it was harmless at that point in time and that repeated scans would indicate when it was time to stop smoking, for 
example, when changes were seen on future imaging. ${ }^{9}$ However, it would seem that this reassurance may not have been felt by the friends and family of study participants as the nodule group appeared to be more likely to report significant others wanted them to stop than the normal CT group. To our knowledge, this is a new finding in the context of lung cancer screening, and one that requires confirmation from other studies. It is also possible that the impact of an abnormal CT result may be more apparent at later follow-up time points. The UKLS reported short and longer term follow-up, finding no impact on smoking cessation in the short term ( 2 weeks post CT result), but a significant impact up to 2 years later in those requiring additional investigations. ${ }^{18}$ This, coupled with the finding of a dose-response relationship between the number of abnormal CT scans and abstinence rates, suggests exploring the impact of pulmonary nodules on smoking behaviour at later time points in the ECLS trial may be useful.

Several lung cancer screening studies have incorporated and evaluated smoking cessation interventions, ${ }^{25-28}$ with some positive findings, and although further research is needed in this area, smoking cessation interventions are recommended, at each screening round, for smokers who take part in lung cancer screening programmes. ${ }^{29}$ One issue to consider is whether providing smoking cessation support as part of a lung cancer screening programme may affect willingness to undergo screening. Lung cancer screening studies, including those in the UK, have shown evidence of participation bias, with lower participation rates in current than ex-smokers. ${ }^{30-32}$ Lower participation rates amongst those at higher risk of lung cancer will impact on the effectiveness of screening programmes. A recent meta-synthesis of qualitative studies exploring cancer screening attendance decisions in the UK found screening can be perceived as an attempt to exert control over individuals, which individuals felt should be resisted..$^{33}$ Focus groups conducted prior to the ECLS trial also found some individuals worried about being coerced into stopping smoking if they took part in lung cancer screening. ${ }^{34}$ It is possible that smokers may decline lung cancer screening because they do not want to stop smoking. It is therefore important that screening information addresses this issue and that smoking cessation provided as part of a lung cancer screening programme is delivered in a sensitive and non-threatening manner.

\section{What this study adds}

Detection of pulmonary nodules on a CT scan following lung cancer screening in the UK does not appear to impact substantially on smoking behaviour. However, receiving a positive Early CDT ${ }^{\circledR}$-Lung test may have reduced smoking prevalence and this possibility will be explored in the main trial analysis. If the UK implements a lung cancer screening programme, this would present an ideal 
opportunity to evaluate the impact of smoking cessation support nested within the screening programme. Our findings suggest research exploring the potential for, and impact of exploiting the greater perceived social pressure to quit in those with pulmonary nodules would be useful. In addition, it would also be important to explore the impact of the information provided to those invited to screening, the impact of providing screening results and abnormal CT findings in the presence of significant others (with appropriate patient consent) and the impact of incorporating smoking cessation on screening uptake and whether this differs by lung cancer risk.

\section{Study limitations}

This is the first study examining the smoking behaviour following detection of pulmonary nodules on a chest $\mathrm{CT}$ scan in those with a positive Early $\mathrm{CDT}^{\circledR}{ }^{-}$Lung test within a UK population. We achieved a very high follow-up rate which was higher than several previous studies, ${ }^{12}, 18,23$ used a range of questions to establish smoking behaviour and adjusted analyses for baseline responses. Our study sample comprised those with positive Early $\mathrm{CDT}^{\circledR}$-Lung test results in the main trial and a post-hoc power calculation indicates it provided $80 \%$ power at the $5 \%$ significance level to detect a difference at 3 months follow-up of $18 \%$ in the proportion reporting smoking in the last month (i.e. $40 \%$ in the nodule group and $58 \%$ in the normal CT group; equivalent to $31 \%$ of smokers stopping smoking). This is similar to quit rates in those with abnormal CT results from several other studies; $62 \%$ in the study by Ostroff ${ }^{10}, 42 \%$ in the study by Townsend, ${ }^{12} 30 \%$ in the UKLS pilot study ${ }^{18}$ and $26 \%$ in the study by Styn, ${ }^{13}$ but higher than quit rates in the Danish LCST $(18 \%)^{23}$ and the NELSON trial $(12 \%) .{ }^{24}$ Our study therefore may not have had adequate power to detect small, but potentially clinically important differences in smoking outcomes. Also, as only a small proportion of participants would have received their CT scan result at the time of completing the 1 month questionnaires, we were unable to explore the immediate impact of pulmonary nodule detection on smoking outcomes.

\section{Funding}

This work was supported by a National Institute for Health Research (NIHR) School for Primary Care Research (SPCR) funded academic clinical fellowship. The views expressed are those of the author(s) and not necessarily those of the NIHR, the NHS or the Department of Health. The ECLS study was supported by the Chief Scientist Office and Oncimmune Ltd. The follow-up data collection was supported by University of Nottingham PhD studentships and by Oncimmune Ltd.

\section{Ethical approval}


Ethical approval was given by the East of Scotland Research Ethics Service as an amendment to the main ECLS study: REC reference 13/ES/0024, amendment number AM16.

\section{Competing Interests}

The University of Nottingham (DK and KV) received funding from Oncimmune Ltd for follow-up data collection. JR has shares and share options in Oncimmune Ltd, but has not had any company involvement for over 2 years.

\section{Acknowledgements}

We would like to thank participants and general practices for taking part in the study. We also thank ECLS trial staff for recruiting participants and collecting baseline data. We gratefully acknowledge the contribution to this study and publication made by the Tayside Clinical Trials Unit (TCTU).

\section{References}

1. Cancer Research UK. Lung cancer statistics. Available from: http://www.cancerresearchuk.org/health-professional/cancer-statistics/statistics-by-cancertype/lung-cancer. Accessed 18/5/18.

2. National Cancer Intelligence Network. Recent trends in lung cancer incidence, mortality and survival. Available from:http://www.ncin.org.uk/publications/. Accessed 18/5/18.

3. The National Lung Screening Trial Research Team. Reduced Lung-Cancer Mortality with LowDose Computed Tomographic Screening. New England Journal of Medicine. 2011; 365:395-409.

4. Nielsen C, Lang RS. Principles of screening. Medical Clinics of North America. 1999; 83:132337.

5. Bach PB, Mirkin JN, Oliver TK, et al. Benefits and harms of CT screening for lung cancer: A systematic review. JAMA. 2012; 307:2418-29.

6. Callister MEJ, Baldwin DR, Akram AR, Barnard S, Cane P, Draffan J, et al. British Thoracic Society guidelines for the investigation and management of pulmonary nodules: accredited by NICE. Thorax. 2015; 70:ii1-ii54.

7. Folch EE, Mazzone PJ. Assessment of solitary pulmonary nodule BMJ Best Practice. 2015.

8. MacMahon H, Naidich DP, Goo JM, Lee KS, Leung ANC, Mayo JR, et al. Guidelines for Management of Incidental Pulmonary Nodules Detected on CT Images: From the Fleischner Society 2017. Radiology. 0:161659.

9. Zeliadt SB, Heffner JL, Sayre G, et al. Attitudes and perceptions about smoking cessation in the context of lung cancer screening. JAMA internal medicine. 2015; 175:1530-7.

10. Ostroff JS, Buckshee N, Mancuso CA, Yankelevitz DF, Henschke Cl. Smoking Cessation Following CT Screening for Early Detection of Lung Cancer. Preventive Medicine. 2001; 33:613-21.

11. Dela Cruz CS, Tanoue LT, Matthay RA. Lung cancer: epidemiology, etiology, and prevention. Clinics in chest medicine. 2011; 32:605-44.

12. Townsend CO, Clark MM, Jett JR, Patten CA, Schroeder DR, Nirelli LM, et al. Relation between smoking cessation and receiving results from three annual spiral chest computed tomography scans for lung carcinoma screening. Cancer. 2005; 103:2154-62.

13. Styn MA, Land SR, Perkins KA, Wilson DO, Romkes M, Weissfeld JL. Smoking Behavior 1 Year after Computed Tomography Screening for Lung Cancer: Effect of Physician Referral for Abnormal CT Findings. Cancer Epidemiology Biomarkers \& Prevention. 2009; 18:3484-9. 
14. Tammemagi MC, Berg CD, Riley TL, Cunningham CR, Taylor KL. Impact of lung cancer screening results on smoking cessation. Journal of the National Cancer Institute. 2014; 106:dju084.

15. Borondy Kitts AK, McKee AB, Regis SM, Wald C, Flacke S, McKee BJ. Smoking cessation results in a clinical lung cancer screening program. Journal of thoracic disease. 2016; 8:S481-7.

16. Clark MA, Gorelick JJ, Sicks JD, Park ER, Graham AL, Abrams DB, et al. The Relations Between False Positive and Negative Screens and Smoking Cessation and Relapse in the National Lung Screening Trial: Implications for Public Health. Nicotine \& tobacco research : official journal of the Society for Research on Nicotine and Tobacco. 2016; 18:17-24.

17. Freiman MR, Clark JA, Slatore CG, Gould MK, Woloshin S, Schwartz LM, et al. Patients' Knowledge, Beliefs, and Distress Associated with Detection and Evaluation of Incidental Pulmonary Nodules for Cancer: Results from a Multicenter Survey. Journal of thoracic oncology : official publication of the International Association for the Study of Lung Cancer. 2016; 11:700-8.

18. Brain K, Carter B, Lifford KJ, Burke O, Devaraj A, Baldwin DR, et al. Impact of low-dose CT screening on smoking cessation among high-risk participants in the UK Lung Cancer Screening Trial. Thorax. 2017; 72:912.

19. Sullivan FM, Farmer E, Mair FS, Treweek S, Kendrick D, Jackson C, et al. Detection in blood of autoantibodies to tumour antigens as a case-finding method in lung cancer using the EarlyCDT ${ }^{\circledR}$-Lung Test (ECLS): study protocol for a randomized controlled trial. BMC cancer. 2017; 17:187.

20. Chapman CJ, Healey GF, Murray A, Boyle P, Robertson C, Peek LJ, et al. EarlyCDT ${ }^{\circledR}$-Lung test: improved clinical utility through additional autoantibody assays. Tumour Biology. 2012; 33:1319-26.

21. StataCorp. Stata Statistical Software. Texas.

22. Slatore CG, Baumann C, Pappas M, Humphrey LL. Smoking behaviors among patients receiving computed tomography for lung cancer screening. Systematic review in support of the U.S. preventive services task force. Annals of the American Thoracic Society. 2014; 11:619-27.

23. Ashraf H, Tønnesen P, Holst Pedersen J, Dirksen A, Thorsen H, Døssing M. Effect of CT screening on smoking habits at 1-year follow-up in the Danish Lung Cancer Screening Trial (DLCST). Thorax. 2009; 64:388-92.

24. van der Aalst CM, van Klaveren RJ, van den Bergh KAM, Willemsen MC, de Koning HJ. The impact of a lung cancer computed tomography screening result on smoking abstinence. European Respiratory Journal. 2011; 37:1466-73.

25. Clark MM, Cox LS, Jett JR, Patten CA, Schroeder DR, Nirelli LM, et al. Effectiveness of smoking cessation self-help materials in a lung cancer screening population. Lung cancer (Amsterdam, Netherlands). 2004; 44:13-21.

26. Ferketich AK, Otterson GA, King M, Hall N, Browning KK, Wewers ME. A pilot test of a combined tobacco dependence treatment and lung cancer screening program. Lung cancer (Amsterdam, Netherlands). 2012; 76:211-5.

27. Taylor KL, Hagerman CJ, Luta G, Bellini PG, Stanton C, Abrams DB, et al. Preliminary evaluation of a telephone-based smoking cessation intervention in the lung cancer screening setting: $A$ randomized clinical trial. Lung cancer (Amsterdam, Netherlands). 2017; 108:242-6.

28. van der Aalst $\mathrm{CM}$, de Koning $\mathrm{HJ}$, van den Bergh KA, Willemsen MC, van Klaveren RJ. The effectiveness of a computer-tailored smoking cessation intervention for participants in lung cancer screening: a randomised controlled trial. Lung cancer (Amsterdam, Netherlands). 2012; 76:204-10.

29. Fucito LM, Czabafy S, Hendricks PS, Kotsen C, Richardson D, Toll BA, et al. Pairing smokingcessation services with lung cancer screening: A clinical guideline from the Association for the Treatment of Tobacco Use and Dependence and the Society for Research on Nicotine and Tobacco. Cancer. 2016; 122:1150-9.

30. Ali N, Lifford KJ, Carter B, McRonald F, Yadegarfar G, Baldwin DR, et al. Barriers to uptake among high-risk individuals declining participation in lung cancer screening: a mixed methods analysis of the UK Lung Cancer Screening (UKLS) trial. BMJ open. 2015; 5. 
31. McRonald FE, Yadegarfar G, Baldwin DR, Devaraj A, Brain KE, Eisen T, et al. The UK Lung Screen (UKLS): demographic profile of first 88,897 approaches provides recommendations for population screening. Cancer prevention research (Philadelphia, Pa). 2014; 7:362-71.

32. The National Lung Screening Trial Research Team Writing committee, Aberle DR, Adams AM, Berg CD, Clapp JD, Clingan KL, et al. Baseline Characteristics of Participants in the Randomized National Lung Screening Trial. Journal of the National Cancer Institute. 2010; 102:1771-9.

33. Young B, Bedford L, Kendrick D, Vedhara K, Robertson JFR, das Nair R. Factors influencing the decision to attend screening for cancer in the UK: a meta-ethnography of qualitative research. Journal of public health (Oxford, England). 2017:1-25.

34. das Nair R, Orr KS, Vedhara K, Kendrick D. Exploring recruitment barriers and facilitators in early cancer detection trials: the use of pre-trial focus groups. Trials. 2014; 15:98. 
Table I. Demographic characteristics at baseline amongst participants in the nodule group and those in the normal $\mathrm{CT}$ group (\% indicates column percentage unless otherwise stated)

\begin{tabular}{|c|c|c|c|}
\hline Characteristics & $\begin{array}{c}\text { Nodule } \\
\mathrm{n}=95(\%)\end{array}$ & $\begin{array}{l}\text { Normal CT } \\
\mathrm{n}=174(\%)\end{array}$ & Statistical Test \\
\hline $\begin{array}{c}\text { Study Centre } \\
\text { Glasgow } \\
\text { Tayside }\end{array}$ & $\begin{array}{l}72(75.8) \\
23(24.2)\end{array}$ & $\begin{array}{c}123(70.7) \\
51(29.3)\end{array}$ & $\chi^{2}(1)=0.80, p=0.37$ \\
\hline $\begin{array}{l}\left.\text { Age (years }- \text { median }\left(I Q R^{*}\right)\right) \\
50-54 \text { years } \\
55-59 \text { years } \\
60-64 \text { years } \\
65-69 \text { years } \\
70-74 \text { years } \\
75-79 \text { years }\end{array}$ & $\begin{array}{l}61(56,67) \\
17(17.9) \\
22(23.2) \\
21(22.1) \\
23(24.2) \\
12(12.6) \\
0(0)\end{array}$ & $\begin{array}{l}60(55,66) \\
37(21.3) \\
48(27.6) \\
31(17.8) \\
40(23.0) \\
15(8.6) \\
3(1.7)\end{array}$ & $\begin{array}{c}z=-1.30, p=0.19 \\
\chi^{2}(5)=4.06, p=0.54\end{array}$ \\
\hline $\begin{array}{l}\text { Gender } \\
\quad \text { Male } \\
\text { Female }\end{array}$ & $\begin{array}{l}39(41.1) \\
56(58.9)\end{array}$ & $\begin{array}{l}80(46.0) \\
94(54.0)\end{array}$ & $\chi^{2}{ }_{(1)}=0.60, p=0.44$ \\
\hline $\begin{array}{l}\text { Smoking Status } \\
\text { Current smoker } \\
\text { Ex-smoker }\end{array}$ & $\begin{array}{l}50(52.6) \\
45(47.4)\end{array}$ & $\begin{array}{l}88(50.6) \\
86(49.4)\end{array}$ & $\chi^{2}(1)=0.10, p=0.75$ \\
\hline Smoking Pack-year (median (IQR)) & $35(26,48)$ & $32.5(25,49)$ & $z=-0.83, p=0.41$ \\
\hline $\begin{array}{l}\text { Ethnic Origin } \\
\text { White British } \\
\text { Other }\end{array}$ & $\begin{array}{c}93(97.9) \\
2(2.1)\end{array}$ & $\begin{array}{c}{[4]} \\
165(97.1) \\
5(2.9) \\
\end{array}$ & $\begin{array}{c}\text { Fisher's exact test } \\
p=1.00\end{array}$ \\
\hline $\begin{array}{l}\text { Marital Status } \\
\text { Single } \\
\text { In a relationship/married/civil partnership } \\
\text { Widowed } \\
\text { Separated/divorced }\end{array}$ & $\begin{array}{l}5(5.3) \\
67(70.5) \\
10(10.5) \\
13(13.7)\end{array}$ & $\begin{array}{c}{[5]} \\
15(8.9) \\
103(61.0) \\
17(10.0) \\
34(20.1)\end{array}$ & $\chi^{2}(3)=3.34, p=0.34$ \\
\hline $\begin{array}{l}\text { Scottish Index of Multiple Deprivation (Rank) } \\
\text { 1-1395 (most deprived) } \\
1396-2790 \\
2791-4186 \\
4187-5581 \\
5582-6976 \text { (least deprived) }\end{array}$ & $\begin{aligned} 35 & (36.8) \\
27 & (28.4) \\
14 & (14.7) \\
8 & (8.4) \\
11 & (11.6)\end{aligned}$ & $\begin{array}{l}68(39.1) \\
42(24.1) \\
27(15.5) \\
23(13.2) \\
14(8.1)\end{array}$ & $\chi^{2}(4)=2.60, p=0.63$ \\
\hline $\begin{array}{l}\text { Prescribed medication for low mood } \\
\text { Yes } \\
\text { No }\end{array}$ & $\begin{array}{c}{[1]} \\
11(11.7) \\
83(88.3) \\
\end{array}$ & $\begin{array}{c}{[4]} \\
30(17.7) \\
140(88.3) \\
\end{array}$ & $\chi^{2}(1)=1.63, p=0.20$ \\
\hline $\begin{array}{l}\text { Age at leaving full-time education } \\
\text { (years - median (IQR)) }\end{array}$ & $\begin{array}{c}{[2]} \\
16(15,16)\end{array}$ & $\begin{array}{c}{[7]} \\
16(15,16) \\
\end{array}$ & $z=0.29, p=0.77$ \\
\hline $\begin{array}{l}\text { Work Status } \\
\text { Employed } \\
\text { Unemployed } \\
\text { Retired/other }\end{array}$ & $\begin{array}{l}40(42.1) \\
16(16.8) \\
39(41.1)\end{array}$ & $\begin{array}{c}{[5]} \\
75(44.4) \\
33(19.5) \\
61(36.1)\end{array}$ & $\chi_{(2)}^{2}=0.70, p=0.70$ \\
\hline $\begin{array}{l}\text { First degree relative with lung cancer } \\
\text { No } \\
\text { Yes }\end{array}$ & $\begin{array}{l}70(73.7) \\
25(26.3)\end{array}$ & $\begin{array}{l}115(66.1) \\
59(33.9)\end{array}$ & $\chi^{2}(1)=1.65, p=0.20$ \\
\hline
\end{tabular}

*Interquartile range. [Missing values] 
Table II. Smoking behaviour at baseline amongst participants in the nodule group and those in the normal CT group (column percentage unless otherwise stated)

\begin{tabular}{|c|c|c|c|}
\hline Smoking Behaviour & $\begin{array}{c}\text { Nodule } \\
n=95(\%)\end{array}$ & $\begin{array}{l}\text { Normal CT } \\
\mathrm{n}=174(\%)\end{array}$ & Statistical Test \\
\hline \multicolumn{4}{|l|}{ Not counting the last week, has smoked in } \\
\hline $\begin{array}{l}\text { the last month } \\
\text { Yes }\end{array}$ & $\begin{array}{c}{[9]} \\
54(62.8)\end{array}$ & $90(58.1)$ & \multirow{2}{*}{$\chi^{2}(1)=0.51, p=0.47$} \\
\hline No & $32(37.2)$ & 65 (41.9) & \\
\hline Has smoked in the last week & [9] & [19] & \multirow{4}{*}{$\chi^{2}{ }_{(1)}=0.16, p=0.69$} \\
\hline Yes & $50(58.1)$ & $86(55.5)$ & \\
\hline No & 36 (41.9) & $69(44.5)$ & \\
\hline Smokes $<30$ minutes after waking & [1] & [2] & \\
\hline No & $11(22.5)$ & $30(35.7)$ & \multirow[t]{2}{*}{$\chi_{(1)}^{2}=2.55, p=0.11$} \\
\hline Yes & $38(77.6)$ & $54(64.3)$ & \\
\hline Number of cigarettes smoked/day & & [1] & \multirow{3}{*}{$z=-1.85, p=0.07$} \\
\hline Median (IQR) & $20(15,25)$ & $15(10,25)$ & \\
\hline $\begin{array}{l}\text { Intends to give up smoking in next four } \\
\text { weeks }\end{array}$ & & [4] & \\
\hline Yes & $17(34.0)$ & $18(22.0)$ & \multirow[t]{2}{*}{$\chi^{2}(1)=2.31, p=0.13$} \\
\hline No / Don't know & $33(66.0)$ & $64(78.0)$ & \\
\hline Confident could give up smoking for good & & [4] & \multirow{3}{*}{$\chi_{(1)}^{2}=3.12, p=0.08$} \\
\hline Certain & $12(24.0)$ & $10(12.2)$ & \\
\hline Not certain / Don't know & $38(76.0)$ & $72(87.8)$ & \\
\hline Continue smoking & & & \multirow{4}{*}{$\chi^{2}(1)=1.18, p=0.28$} \\
\hline I would like to keep smoking / Don't & & {$[4]$} & \\
\hline know if I want to stop & $16(32.0)$ & $34(41.5)$ & \\
\hline I would like to stop smoking & $34(68.0)$ & $48(58.5)$ & \\
\hline Thinking about stopping smoking & & [4] & \multirow{3}{*}{$\chi^{2}(1)=3.31, p=0.07$} \\
\hline Not thinking about/trying to stop & $27(54.0)$ & $31(37.8)$ & \\
\hline Thinking about or trying to stop & $23(46.0)$ & $51(62.2)$ & \\
\hline Thinks health will improve if stops smoking & & [4] & \multirow{3}{*}{$\chi^{2}(1)=0.51, p=0.48$} \\
\hline Disagree /Don't know & $9(18.0)$ & $11(13.4)$ & \\
\hline Agree & $41(82.0)$ & $71(86.6)$ & \\
\hline $\begin{array}{l}\text { People important to participant want them } \\
\text { to stop smoking }\end{array}$ & & [4] & \multirow{3}{*}{$\chi_{(1)}^{2}=0.0005, p=0.98$} \\
\hline Disagree /Don't know & $8(16.0)$ & $13(15.9)$ & \\
\hline Agree & $42(84.0)$ & $69(84.1)$ & \\
\hline Tried to cut down in the last month & [2] & [5] & \multirow{3}{*}{$\chi^{2}(1)=0.06, p=0.81$} \\
\hline Yes & $33(68.8)$ & $54(66.7)$ & \\
\hline No & $15(31.3)$ & $27(33.3)$ & \\
\hline Tried to stop in the last month & & [5] & \multirow{3}{*}{$\chi_{(1)}^{2}=0.36, p=0.55$} \\
\hline Yes & $13(26.0)$ & 25 (30.9) & \\
\hline No & $37(74.0)$ & $56(69.1)$ & \\
\hline
\end{tabular}

[Missing values] 


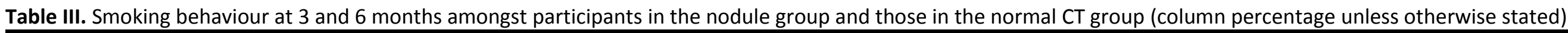

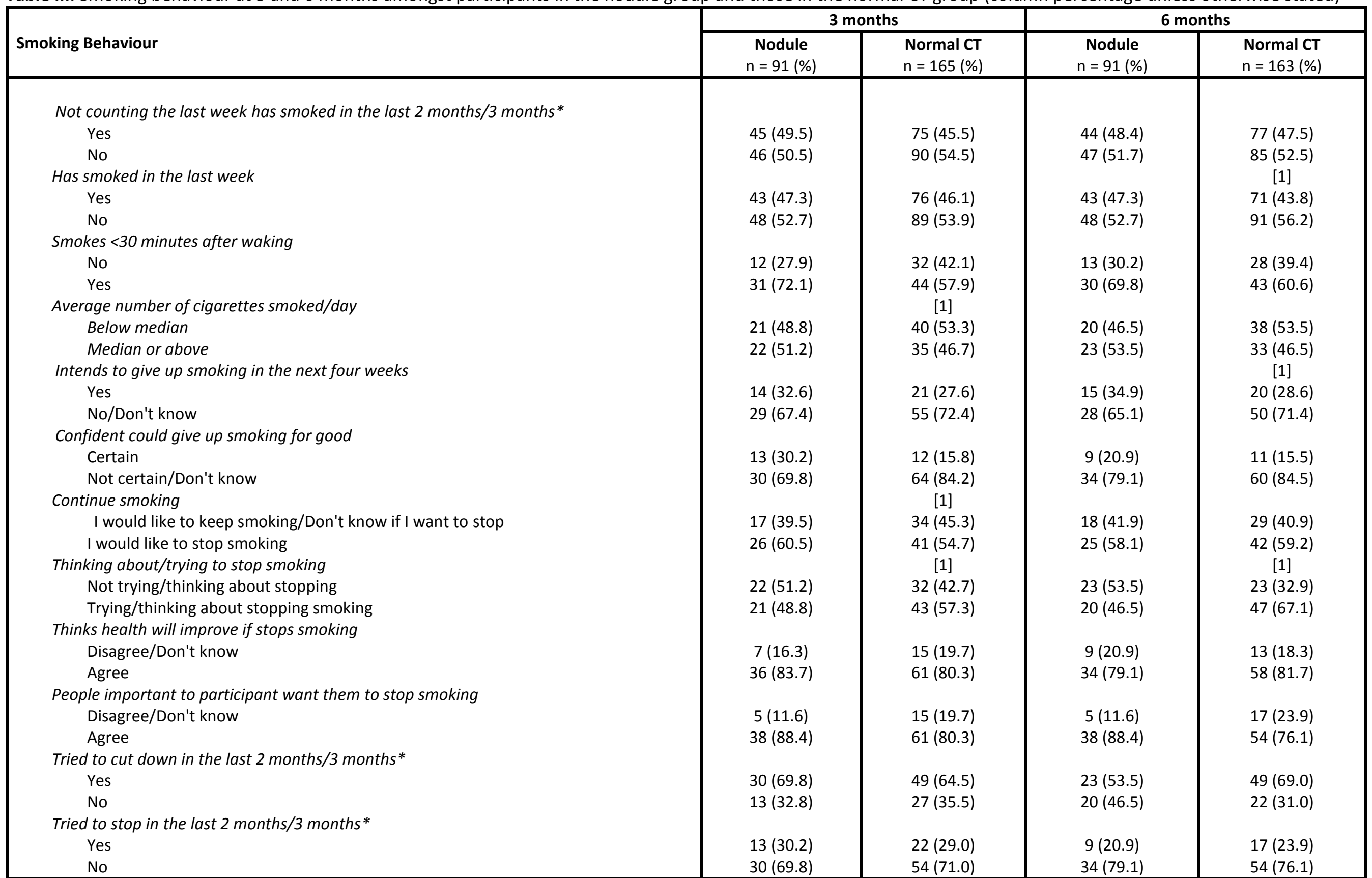

*Reporting time period was since last questionnaire, i.e. 2 months reporting period at 3 months follow-up and 3 months reporting period at 6 months follow-up. [Missing values] 


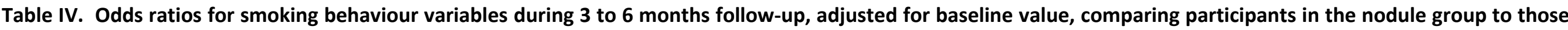
in the normal CT group

\begin{tabular}{|c|c|c|}
\hline Smoking behaviour & $\begin{array}{c}\text { Adjusted odds ratio } \\
(95 \% \mathrm{Cl})\end{array}$ & $\begin{array}{c}\text { P-value for difference } \\
\text { between odds ratios at } 3 \\
\text { and } 6 \text { months }\end{array}$ \\
\hline Not counting the last week, has smoked in the last 2 months $/ 3$ months* & $0.81(0.33,2.00)$ & 0.22 \\
\hline Has smoked in the last week & $1.02(0.46,2.30)$ & 0.71 \\
\hline Smokes $<30$ minutes after waking & $1.02(0.40,2.58)$ & 0.42 \\
\hline Smokes $\geq$ median number of cigarettes/day & $1.26(0.55,2.90)$ & 0.47 \\
\hline Intends to give up smoking in next four weeks & $1.48(0.66,3.32)$ & 0.89 \\
\hline Confident could give up smoking for good & $1.91(0.80,4.58)$ & 0.22 \\
\hline Would like to stop smoking & $0.98(0.46,2.08)$ & 0.21 \\
\hline Thinking about or trying to stop smoking & $0.76(0.38,1.54)$ & 0.11 \\
\hline Thinks health will improve if stops smoking & $1.16(0.51,2.65)$ & 0.61 \\
\hline People who are important to participant want them to stop smoking & $3.04(0.95,9.73)$ & 0.25 \\
\hline Tried to cut down in the last 2 months/3 months* & $0.82(0.40,1.66)$ & 0.06 \\
\hline Tried to stop in the last 2 months/3 months* & $1.49(0.66,3.39)$ & 0.58 \\
\hline
\end{tabular}

*Reporting time period was since last questionnaire, i.e. 2 months reporting period at 3 months follow-up and 3 months reporting period at 6 months follow-up. 